\title{
"It didn't matter what the bill said...": Influences on abortion policy legislative decision-making in Georgia
}

\author{
Erica Barton, $\mathrm{MPH}^{1}$, Subasri Narasimhan, $\mathrm{PhD}, \mathrm{MPH}^{1,2}$, and Dabney P. Evans, $\mathrm{PhD}, \mathrm{MPH}^{1,2}$ \\ ${ }^{1}$ Rollins School of Public Health, Emory University, Atlanta, GA; ${ }^{2}$ Center for Reproductive Health Research in the Southeast \\ Corresponding Author: Dabney Evans • Rollins School of Public Health, Emory University • Atlanta, GA • Telephone: (404) 849-5643 • Email: \\ dabney.evans@emory.edu
}

\section{ABSTRACT}

Background: In March 2019 the Georgia legislature passed HB 481 described as a "heartbeat bill", prohibiting abortion at around six weeks gestation. Given the prevalence of anti-abortion legislation and the public health implications of abortion restrictions, we sought to understand how Georgia legislators made decisions on this early abortion ban legislation.

Methods: We conducted in-depth interviews with nine legislators from the Georgia House of Representatives who participated in the 2019 legislative session. In-depth interviews were conducted in-person and over the phone. Interview recordings were transcribed verbatim and inductive codes identified. Codes focused primarily on views of: abortion in general; specific abortion policy; and how information about HB 481 was obtained. A thematic analysis was performed to elucidate legislators' perspectives.

Results: Legislators had clear considerations that differed by party affiliation. Democrats described concerns with HB 481 grounded in reproductive autonomy and justice. They claimed concern with the lives of pregnant persons citing the physical and emotional harm bills like HB 481 cause. They questioned the medical evidence used to support HB 481 and argued that it violated the freedom to choose when to have children. Republican legislators evoked a similar harm reduction framework, but were concerned with protecting the lives of the unborn, arguing that a fetus should be considered a person once a "heartbeat" is detected and that abortion after this point is equal to killing a person. Republicans also described aligning with their constituents' values. Despite the arguments and evidence presented during the legislative session, legislators voted according to their previously held beliefs on abortion.

Conclusions: Controversial abortion legislation is commonplace, bringing with it heated debates on when life begins and how to protect it. It is important to understand the underlying motives for legislators' decisions to enhance communication and improve policy outcomes related to reproductive health and rights.

Keywords: Abortion, abortion policy, legislative decision-making, reproductive health, qualitative research.

\section{INTRODUCTION}

In 1973, companion Supreme Court cases, Doe v. Bolton and Roe v. Wade legalized abortion in the United States by protecting a woman's right to privacy (Doe v. Bolton, 1973 \& Roe v. Wade, 1973). Doe v. Bolton challenged Georgia's strict abortion laws and, ultimately, legalized abortion by a licensed physician when: pregnancy would endanger the life of the mother or would seriously and permanently affect her health, the fetus would be born with a "grave, permanent, and irremediable mental or physical defect", or in cases where the pregnancy resulted from rape (Doe v. Bolton, 1973). Roe v. Wade established abortion protections throughout pregnancy specifically holding that during the first trimester, abortion is solely the woman's decision and cannot be prohibited or regulated (Roe v. Wade, 1973). In 1992, Planned Parenthood of Southeastern Pennsylvania v. Casey upheld the Roe decision prohibiting abortion bans before fetal viability, and stated that state restrictions could not place an "undue burden" on someone seeking an abortion (Planned Parenthood v. Casey, 1992).

Since the Roe decision, states have consistently passed laws to limit abortion access, testing the legal limits of the constitutional standard and restricting, "whether, when, and under what circumstances a woman may obtain an abortion," (Reingold, 2019). Such laws include gestational limits on abortion, the prohibition of public funding for abortion services, and conscientious objection policies (Guttmacher, 2020). Other laws aim to restrict abortion at the source through targeted restriction on abortion providers (TRAP laws) (Planned Parenthood, 2019). TRAP laws have been deemed unnecessary to provide safe abortion care and are implemented to make abortion less accessible (NARAL, 2020, Whole Woman's Health v. Hellerstedt, 2016 \& June Medical Services v. Russo, 2020). 
Proposed state legislation is increasingly brazen and aimed at overturning Roe. Anti-abortion advocates have recently introduced drastic abortion legislation motivated by previous success in passing abortion restrictions and the addition of conservative justice Brett Kavanaugh to the Supreme Court (Kelly, 2019 \& Lai, 2019). In 2019, nine states passed legislation to ban abortion altogether or at early points in pregnancy, well before the point of viability (Guttmacher, 2019 \& Lai, 2019). These laws include "heartbeat bills" that would ban abortion once fetal cardiac activity is detected, as early as six weeks into pregnancy (Rewire, 2019). Georgia House Bill 481 (HB 481), the Living Infants Fairness and Equality (LIFE) Act, was one such bill. HB 481 extends personhood to embryos and fetuses with detectable cardiac activity and prohibits abortion after this point. While there are exceptions for pregnancies that occur due to rape or incest, or if an abortion is necessary to preserve the mother's life (HB 481, 2019) HB 481 effectively bans abortion in the state of Georgia after six weeks gestation.

Abortion restrictions and bans like HB 481 have troublesome consequences; when abortion is restricted or banned, illegal and unsafe abortions occur. Twenty-five million unsafe abortions happen globally each year, with seven million resulting in complications (World Health Organization, 2019). Unsafe abortions occur when there are barriers to accessing safe abortion. These barriers include restrictive laws and unnecessary requirements (World Health Organization, 2019). In the United States, before abortion was legalized, illegal abortions were not uncommon (Guttmacher, 2019); between 1972-1974 the U.S. Centers for Disease Control and Prevention (CDC) found a drastic reduction in unsafe abortion after abortion was legalized (CDC, 1976). Additionally, the United Nations (UN) has protected the right to health and abortion respectively through General Comment 14: The Right to the Highest Attainable Standard of Health (2000) and General Comment 22 on The Right to Sexual and Reproductive Health (General Comment 22, 2016).

Despite current public health knowledge on the importance of safe abortion care, abortion access in the U.S. remains contingent on the choices in state legislatures. Many factors affect how individual legislators make decisions, but due to the demands and constraints of the legislative session, decisions need to be made quickly and efficiently. Since legislators do not typically have time to collect a breadth of information or consider all possibilities surrounding an issue, they are likely to make decisions under the condition of "bounded rationality," once they are satisfied with their knowledge. Satisficing is based on individuals' cognitive limitations, as well as their personal motivations (Stevens, 2019). Through satisficing, legislators are likely seeking information that is easily accessible and that they trust, and that usually aligns with their current beliefs (Mooney, 1991); in research terms, legislators engage in a form of confirmation bias. Recent studies on legislative decision-making, including on abortion-related legislation, found that many factors can influence legislators, but trust, personal experience, and constituents were highly influential
(Canfield-Davis, 2010, Clement, 2018, \& Woodruff, 2019). We examined what factors influenced legislators' decision-making in the legislative debates on HB 481. Given the prevalence of anti-abortion legislation and the public health implications of abortion restrictions, we wanted to understand how legislators viewed evidence and subsequently made decisions on HB 481 and similar early abortion bans.

\section{METHODS}

\section{Participants}

Nine legislators from the Georgia House of Representatives were interviewed on their personal experiences, perceptions, and decision-making related to $\mathrm{HB} 481$. Two legislators from the Atlanta area were interviewed during the pilot phase and included in the final sample. Seven participants were chosen through a random sample of legislators. A proportionate number of Democrat and Republican representatives, seventeen in all, were contacted via email and phone and asked to participate. From this sample, four additional Democrats and three additional Republicans agreed to be interviewed.

\section{Instrument}

An original in-depth interview guide and demographic survey were developed for this project. The interview guide was tested through in-person cognitive interviews with six individuals working in local reproductive health and advocacy organizations in Atlanta who had experience communicating with legislators about abortion policy. After refining the guide, two pilot interviews were conducted with local legislators; the pilot interviews did not result in any changes to the interview guide.

\section{Data collection}

All interviews were conducted in Atlanta, Georgia between October and December of 2019. Two interviews were conducted in-person at the state Capitol and seven were conducted via phone or Zoom. A confidentiality statement was read to participants prior to the interview and participants were asked permission to be voice recorded. Participants gave their consent orally before interviews were recorded using Voice Memos. Audio files were transcribed verbatim using Happy Scribe and manually checked for accuracy by the first author. The demographic survey was filled out by participants themselves or administered orally immediately following the interview.

\section{Analysis}

Interviews ranged from 21 to 64 minutes and transcripts were coded by the first author using MAXQDA 2020 (VERBI Software, 2019). Preliminary codes were identified and applied to two transcripts. Next, code definitions were created for accuracy and consistency and were compiled in a code book. Codes were inductive, and focused primarily on views of abortion in general, views of specific abortion 
policy, and how information influencing these views was obtained. The code book was reviewed by the senior author and revised. Revised codes were tested on a second transcript and refined before coding the remaining transcripts. Themes were agreed on during memoing and collaborative discussion and all authors agreed on final results through discussion.

\section{Institutional Review Board Approval}

The Emory University Institutional Review Board deemed this study exempt from review due to its nature as a part of public health practice.

\section{RESULTS}

Participants in this study $(\mathrm{N}=9)$ were state legislators representing areas in North, South, and Western Georgia, as well as parts of Metropolitan Atlanta. They had between 1 and 29 years of experience as legislators with a mean of nine years. For three participants, the 2019 legislative session was their first. The sample included six females and three males, and participants identified as African-American or Black, and White. They were married, single, and divorced, and most reported having children. Based on party affiliation three participants were Republican and six were Democrat. All Republicans voted in favor of HB 481 and all Democrats voted against the bill. Four themes emerged inductively from the data. These included: factors influencing decision-making; the influence of existing beliefs about abortion on views of HB 481; perceptions of communication about $\mathrm{HB} 481$; and the effect of party affiliation on views of HB 481.

\section{Factors that influenced legislators' decision-making}

Four factors influenced legislators' decision making when voting on HB 481: personal values including views on abortion; rights and the law; evidence; and their constituents. Personal values were the most commonly cited influences in how legislators voted. These included religious or faith beliefs about when life begins and the value of, "the life of the unborn."

"I feel like life is precious. And, to take a life, someone making a decision to take a life, is wrong. It's immoral. You know, you cannot make a decision to take someone else's life. I don't care how old they are. Or who they are. Or how they are related to you. It's not your right to do that." - Republican

Conversely, views on women's autonomy and personal choice were also part of personal values.

"If we value life, we should value all life. Mother as well as the child. And then of course at the end of the day these are very personal decisions that have to be made and women should be able to have the freedom to make those decisions based upon the advice and consent of their doctor and their and their husbands and other family members and in line with their own faith tradition." - Democrat
Rights and the law were other influential factors. These included discussion of reproductive rights and freedom as universal, and the potential negative impact of removing those rights.

"Reproductive Justice is part of something that I am very serious about. And so, when we started hearing at the beginning of session that this bill was on the table, that would restrict a woman's right to have that access for her body... We didn't really know if it was going to get a committee hearing and where this bill was going. But as it progressed further into the legislative session we knew that this bill was becoming a major piece of legislation that we needed to take a strong stance against." - Democrat

This theme also included the view of current abortion law in the U.S. as sufficient, including among one Republican who voted for HB 481, and the view that bills like HB 481 are unconstitutional.

"There's been a benchmark here for years, cause of the Supreme Court rulings, that you can't do anything to tamper with a woman's right in that first trimester. I've always accepted that as a pretty damn good solution." - Republican

Evidence of various kinds was used by both supporters and opponents of HB 481 and tended to affirm previously held beliefs. Those who supported HB 481 used the presence of fetal cardiac activity, "heartbeat", as proof of life.

"So, if a doctor can find that heartbeat at six weeks then it's true heartbeat. But most of the time it's going to be closer to eight weeks. So, it's not really a date for saying timewise. It's when that heartbeat is heard. And when there is a heartbeat, this baby has its own special $D N A$. It has already started forming all its parts and it has a heartbeat."

- Republican

Those who opposed HB 481 used medical evidence that the heart organ was formed later in fetal development to support their position opposing the bill. Opponents of HB 481also cited evidence that abortion restrictions do not stop abortion from happening and that such restrictions are known to increase unsafe abortion.

"Doctors were coming down, in particular, because doctors were like, you know, first of all this is a horrible decision, speaking from a medical perspective, because when you tell people they cannot get the health care that they have decided they want...women will just take matters into their own hands and things go back to what we saw pre-1970, when Roe v. Wade was decided, where hospitals had whole septic wards devoted to women who had given themselves abortions at home." - Democrat

Surprisingly, constituents did not have a significant influence on legislators' voting decisions. Rather, constituents and their legislators tended to share the same beliefs about abortion. However, one participant voted on HB 481 counter to their own beliefs and in the interest of their constituents. 
"If your constituency speaks, and they speak loud enough, you know, just get on with it."

- Republican

\section{Existing beliefs about abortion influenced views of $\mathrm{HB}$ 481}

Although interviews focused on legislators' experiences with HB 481 specifically, it was clear that legislators held existing positions on the issue of abortion. Participants either directly opposed or supported abortion rights, and some considered new restrictions unconstitutional. Those opposed to abortion argued that fetuses are living beings and that all life has value. One participant shared their view,

"I always had a problem with abortion... when does it go from just a fertilized egg, not a being, to becoming a being?" - Republican

Those supportive of abortion rights cited the importance of women's autonomy and reproductive rights,

"Reproductive rights and justice... are two issues that I've worked on heavily, so I know the ins and outs of what happens when you restrict reproductive freedom." - Democrat

Some simply believed that the matter was settled law and that HB 481 was unconstitutional. One participant citing Roe v. Wade stated,

"Well, I didn't think the bill should be written at all because this is already settled case law. And it's already been established that women have a constitutional right to reproductive health." - Democrat

\section{Communication surrounding HB 481 was not effective in changing legislators' beliefs}

Participants described having communication with colleagues, constituents, experts, and special interest groups on HB 481 during the 2019 legislative session. Legislators communicated with their colleagues through personal conversations and by listening to community testimony and legislative debate. Many participants had conversations with colleagues who supported the bill as well as those who opposed it. Participants also described conversations with constituents on both sides of the issue. Expert testimony was an active form of communication. The majority of participants discussed hearing from doctors presenting medical evidence in opposition to HB 481. Less frequent were legislators' experiences with special interest groups. Three legislators discussed having conversations with members of these groups, which included reproductive rights advocacy organizations and pro-life crisis pregnancy centers. Legislators only discussed speaking to groups whose position aligned with their prior beliefs about abortion.

Despite multiple pathways of communication from a wide range of actors, legislators' positions were not swayed. Arguments either reaffirmed participants' beliefs or were dismissed:
"You know, it's called the heartbeat bill because it says ... a baby is a human being once the heartbeat is detected. You know, we did hear testimony in the Health and Human Services from the $O B / G Y N$ group specialists saying they question whether that was a true heartbeat or rather just move down fluid to a developing area of the heart. But, you know, it was contentious to say the least." - Republican

\section{Democrats' views on HB 481 were similar and Republicans' views were varied}

All Democratic participants supported a person's decision to choose to continue a pregnancy or not. Most also discussed their support of reproductive freedom and rights, which related to the belief that all people should have the right to make their own decisions about their sexual and reproductive health. Legislators condemned HB 481 for trying to remove those rights, as one participant shared,

"It legislates my right to choose. When I'm sitting down to feed my family, I don't call you and ask you what's for dinner. When a person is having sex with their partners, are they all going to need the government say, listen how many times a week should I? Or shouldn't I? You know, no you're not! So, why are you telling me what to do? You don't know my circumstance. My choices. Yes, every life is valued. I am 100 percent clear on that. Every life is valued, but there are choices people need to make." - Democrat

Participants opposed to the bill also discussed the impacts of restricting abortion access and the potential harm that $\mathrm{HB}$ 481 may cause.

"There are so many ramifications that are ripple effects that affect everybody, even if you don't have a uterus, that are connected to these bills, and I know that they don't know that information. So, to me, I knew that this bill [would] be a death sentence for women. I knew it would be a bill that would basically set a policy of forced birthing for women." - Democrat

Legislators cited Georgia's high maternal mortality rate as further evidence that reproductive rights in the state should be protected. Specifically, legislators were concerned about the disproportionately high maternal mortality rate among Black women in Georgia and the implications of HB 481 on maternal mortality.

"We know that Black women are dying three to four times more giving birth to kids they want. And there was no outrage about making sure that we find out what the reason is and making sure that Black women have the kind of health care that allows them to bring their children to fruition if they wanted to have children...They talk about life, but it's only certain life and the life inside of a woman, not the life that comes out of a woman."

- Democrat

Legislators described their personal experiences with abortion and parenting when discussing their views of 
abortion. One participant shared her thinking relative to her own abortion,

"So, my experience wasn't, oh my gosh I'm so sad. Yes. It was the value of a life. But, I also understood that the value of bringing a life to fruition was a higher cost than I had. The financial resources, the physical, the emotional resources...I did not have that support."

- Democrat

All Republican participants voted in favor of HB 481, but they did not all support the bill for the same reasons. Two participants discussed the value of the life of the unborn and disagreed that someone should be able to choose to end a pregnancy. One legislator had a personal experience as a young mother that solidified her beliefs:

"I had complications from the pregnancy. I had pre-eclampsia. I had all kinds of things, reasons why I could have said no. I had anemia, which I still have today. So anyway, I just feel like, inconvenient or not, there's a purpose to everything. There's a season and a purpose to everything in life and that life needs to be valued." - Republican

Other legislator's beliefs were reinforced through the legislative session and the presentation of "heartbeat science." One legislator who expressed his opposition to abortion said of the evidence presented:

"And I wished it was something different. I wished that the fetus was not developing as fast as it did, and it wasn't a living fetus until, you know, 8 or 10 weeks or something like that. But that's not the case."

- Republican

One Republican was personally opposed to HB 481 and said that it should not have been introduced due to the existence of Roe v. Wade. He also expressed support for individual choice. Ultimately, he voted in support of the bill because of his pro-life constituency.

"But, a lot of us couldn't NOT vote for it. They'd skin us alive ... I got more damn churches than a dog's got fleas [in my district]." - Republican

Existing, strongly-held beliefs about abortion make abortion legislation controversial and challenging. The communication strategies used by legislators, lobbyists, and activists did not change existing beliefs and different approaches will be needed to affect abortion legislation in the future.

\section{DISCUSSION}

Interviews with legislators on their experiences with $\mathrm{HB}$ 481 reveal decision-making around abortion legislation may be different than decision-making on other types of policy because of the strength of legislators' existing beliefs and personal opinions about abortion. Legislators' existing beliefs influenced their views on HB 481 and were not changed through the legislative process or the communications strategies of advocates on opposing sides of the issue. Understanding legislators' views, the factors they are considering, and the importance of those factors is key for activists and advocates who hope to sway policy making outcomes. Shifting communication strategies relative to these factors may help advance reproductive rights by preventing the passage of anti-abortion policies.

Previous research on legislative decision-making found that fiscal impact, trust, constituents, timing of when a bill is introduced, committee chairs, legislative leadership, sources of information, sponsor, regionalism, governor, interest groups, lobbyists, sources of voting advice, re-election, state agency bureaucrats/civil servants, religion, legislative staff, and media are all key factors that influence legislative decision-making (Canfield-Davis, 2009). Another study found constituents and expert testimony to be the most influential factors, while media was the least influential (Clement, 2018). We found that trust, constituents, sources of information, interest groups, lobbyists, religion, and re-election play a role in decision-making on abortion policy, as well. Legislators cited evidence, either "heartbeat" or medical, personal values, rights and current law, and constituents as their reasons for supporting or opposing HB 481. However, each participant had existing views on abortion and, with the exception of one participant, their votes on HB 481 were in line with those prior views. This suggests that, for many legislators, previously held personal beliefs are more influential when it comes to making decisions about abortion policy. Reproductive health and justice advocates may consider utilizing values clarification and transformation exercises with legislators to encourage personal reflection on abortion related values and beliefs change at the individual level (National Abortion Federation, $2005 \&$ Turner and Page, 2008).

Personal experience with abortion, pregnancy, and parenthood played an important role in influencing views on abortion. These are common experiences that are easy to draw from and connect to beliefs about abortion. This was true for men and women ${ }^{1}$, but much more salient among women. One male legislator jokingly cited his large family as evidence that he was "pro-child." For female legislators, having children was tied to their experiences and identities as women thus affecting their abortion opinions. Experiences of womanhood often arose among Democrat legislators who were displeased with the fact that men were at the helm of advancing HB 481, specifically the governor of Georgia and the primary sponsor of the bill. Their experiences as mothers demonstrated their authority on women's reproductive issues like abortion, something that men, they argued, could not possess. Although male legislators had personal experiences as parents, they relied more on their religious views, constituency, and the secondhand experiences of women when making decisions about abortion policy. One male legislator acknowledged his lack of experience and deferred to female legislators when it came to HB 481.

\footnotetext{
${ }^{1}$ The terms "men" and "women" are used interchangeably here with "male" and "female", which denote biological sex.
} 
Given that personal experiences have such influence on legislators' own beliefs, it may be useful to incorporate legislator role-playing and increased abortion storytelling into the pro-choice strategy. HB 481 supporters used personal narratives to argue for the bill, while opponents relied on medical evidence and expert testimony. It may be more influential to combine the two by using destigmatizing and/or positive abortion storytelling along with the presentation of scientific evidence. Similarly, given that female gender norms are often associated with motherhood, adopting a gender transformative approach in discussions with legislators may influence their thinking and actions relative to abortion which is intricately tied to gender and power (Rutgers, 2020 \& Muralidharan, Fehringer, Pappa, Rottach, Das, and Mandal, 2015).

Despite the discussions surrounding HB 481 and the evidence presented, legislators' views weren't changed. Woodruff (2019) found that evidence was not useful in changing legislators' views on abortion policy, but rather "beliefs drive evidence claims." Woodruff (2019) also found that legislators trusted evidence from sources they already considered trustworthy, affirming legislator's confirmation bias. We similarly found that evidence affirmed legislators existing beliefs and legislators sought information from sources they trusted; opposing evidence dismissed. Opponents of HB 481 primarily used expert testimony and medical evidence to argue against the bill. Those who supported the bill used "heartbeat" evidence and personal testimony in their arguments. Opponents -- with the scientific and medical communities at their back -- were not swayed by the emotional pull of pro-lifers. Similarly, the belief that abortion is murder, backed by "heartbeat science", could not be explained away by medical experts. This reinforces the idea that personal experience and existing beliefs matter more when it comes to abortion policy. Therefore, communication strategies on both sides of the issue seemed to miss the mark and were not successful in changing the other's view.

Because personal beliefs are deeply ingrained, efforts at influencing legislators may consider focusing on culture and norms change in the long term at structural levels while focusing on values clarification and transformation at the individual level in the short term.

Similarly, opponents of anti-abortion legislation can consider incorporating emotional elements into their messaging by presenting personal narratives. These may include abortion stories, as well as experiences with pregnancy and childbirth.

Advocacy efforts similarly appeared unsuccessful in swaying legislators' decision making. Protests were common throughout the 2019 legislative session. Most protesters opposed HB 481 and held signs telling legislators to "Trust Women." News articles and social media posts covering HB 481 always included pictures of protestors. Pro-choice advocates applauded the protesters and hundreds of people showed up to the Capitol to protest as the legislative session wore on. While protests certainly drew attention to HB 481, our study found that protests were not a factor that legislators said influenced their views or decision-making, although HB 481 passed by a very slim margin. Only Republican participants discussed protestors in their interviews and all viewed protestors as confrontational and hostile. While this intense public pressure may have influenced the five Republican legislators who abstained from the bill we cannot attribute their abstentions to any specific cause since none of them were participants in this research; the same is true of the one Democrat who voted in favor of HB 481.

Pro-choice advocates can consider changing their tactics in order to more effectively communicate to legislators about abortion and related policy. Advocates should promote dialogue and mutual understanding with legislators, and avoid confrontational communication. Likewise, given that the legislators in our study only spoke to advocacy organizations with whom their existing beliefs aligned, such organizations may consider more actively reaching across the aisle to attempt meaningful engagement and values transformation with legislators in the "mushy middle" as well as those with opposing views. At a minimum such engagement would provide insights into diverse viewpoints and at best some common ground may be identified.

There are several limitations to this study. Because HB 481 passed the House by a thin margin, our study originally aimed to understand the factors that influenced legislative decision-making among outliers: legislators who acted counter to their party and could potentially swing the vote. We identified nine candidates who voted counter to their party (i.e. Democrats who voted for $\mathrm{HB} 481$ and Republicans who abstained or were excused or absent from voting and expressed opposition to the bill). We contacted this sample first, but only received one positive response. Unfortunately, this participant passed away before the interview could be conducted. Because of the lack of positive responses, the study shifted to include participants who voted in line with their party, and a random sample was conducted. Future research on outliers will offer more insight into the factors that influence legislative decision-making and where opportunities lie to swing abortion policy.

Because of time constraints, the sample size is small and more Democrats than Republicans were interviewed. We aimed to recruit a proportionate number of legislators from each party. Since Georgia's House of Representatives has 105 active Republican legislators and 75 Democrats, we would have ideally recruited more Republicans than Democrats. However, a higher percentage of Democrats responded to requests to be interviewed. Saturation was reached among Democrat participants, with common themes recurring and no new data surfacing. Saturation was not reached among Republican participants, as new data emerged in each interview. Given more time, we would have focused on recruiting more Republicans, and interviewed until reaching saturation. 


\section{CONCLUSION}

Abortion is a safe, medical procedure, and should be widely viewed as necessary health care. Yet most legislators made decisions about HB 481 based on their personal beliefs, rather than medical, scientific, or legal information. This presents challenges for reproductive rights advocates and pro-choice legislators, who relied heavily on medical evidence and expert testimony to oppose HB 481. In order to advance reproductive rights and access to reproductive healthcare, pro-choice advocates should adjust their strategies by incorporating personal narratives alongside scientific evidence and attempting values clarification and transformation among legislators.

\section{References}

Canfield-Davis, K., Jain, S., Wattam, D., McMurtry, J., \& Johnson, M. (2010). Factors of influence on legislative decision making: A descriptive study-updated August 2009. Journal of Legal, Ethical and Regulatory Issues, 13(2), 55-68.

Clement, D. M. (2018). Factors Influencing Georgia Legislators' Decision-Making on Nurse Practitioner Scope of Practice.

Policy, Politics, \& Nursing Practice, 19(3-4), 91-99.

Doe v. Bolton, 410 U.S. 179 (1973).

Guttmacher Institute. (2020). An Overview of Abortion Laws. Retrieved from

https://www.guttmacher.org/state-policy/explore/overview-abort ion-laws

HB 481 Living Infants Fairness and Equality (LIFE) Act, H.B. 481, O.C.G.A. 5.6.34; (2019)

June Medical Services v. Russo, 591 U.S. _ (2020).

Kelly, C. (2019, October 29). States passed a flurry of new abortion restrictions this year. Here's where they stand. CNN. Retrieved from

https://www.cnn.com/2019/10/27/politics/abortion-laws-states-r oundup/index.html

Lai, K. (2019, May 29). Abortion Bans: 9 States Have Passed Bills to Limit the Procedure This Year. The New York Times.

Retrieved from

https://www.nytimes.com/interactive/2019/us/abortion-laws-stat es.html

Muralidharan, A., Fehringer, J., Pappa, S., Rottach, E., Das, M., and Mandal, M.. (2015). Transforming Gender Norms, Roles, and Power Dynamics for Better Health: Evidence from a Systematic Review of Gender-integrated Health Programs in Low- and Middle-Income Countries. Washington DC: Futures Group, Health Policy Project.

Mooney, C.Z. (1991). Information Sources in State Legislative Decision Making. Legislative Studies Quarterly, 16(3): 445-455.

Nash, E., Mohammed, L., Cappello, O., and Naide, S. (2019). State Policy Trends 2019: A Wave of Abortion Bans, But Some States
Are Fighting Back. Guttmacher Institute [Online]. Retrieved from

https:/www.guttmacher.org/article/2019/12/state-policy-trends2019-wave-abortion-bans-some-states-are-fighting-back

NARAL. (2020). TRAP Laws. Retrieved from https://www.prochoiceamerica.org/issue/trap-laws/

National Abortion Federation. (2005). A Values Clarification Guide for Health Care Professionals. Retrieved from https://prochoice.org/resources/the-abortion-option-a-values-clar ification-guide-for-health-professionals/.

Office of the High Commissioner of Human Rights. CESCR General comment No. 14 The right to the highest attainable standard of health (11 August 2000).

Office of the High Commissioner of Human Rights. CESCR General comment No. 22 on the Right to Sexual and Reproductive Health (article 12 of the International Covenant on Economic, Social and Cultural Rights). (2 May 2016).

Planned Parenthood v. Casey, 505 U.S. 833 (1992).

Planned Parenthood. (2020). What are TRAP laws? Retrieved from https://www.plannedparenthoodaction.org/issues/abortion/trap-la ws

Reingold, R. (2019). State Abortion Restrictions and the New Supreme Court Women's Access to Reproductive Health Services. JAMA, 322(1), 21-22.

Rewire. (2019, May 30). Legislative Tracker Heartbeat Bans. Rewire News. Retrieved from https://rewire.news/legislative-tracker/law-topic/heartbeat-bans/

Roe v. Wade, 410 U.S. 113 (1973).

Rutgers. (2020). Gender Transformative Approach. Retrieved from https://www.rutgers.international/GTA

Stevens, D. (2019). Satisficing in Political Decision Making. Oxford Research Encyclopedias. Retrieved from https://oxfordre.com/politics/view/10.1093/acrefore/9780190228 637.001.0001/acrefore-9780190228637-e-1020

Turner, K.L. and Page, K.C. (2008). Abortion Attitude Transformation: A Values Clarification Toolkit for Global Audiences. Chapel Hill, NC, Ipas.

United States Centers for Disease Control, DHEW (CDC). (1976). Abortion Surveillance, Annual Summary 1974. Atlanta, Georgia.

VERBI Software. (2019). MAXQDA 2020 [computer software]. Berlin, Germany: VERBI Software. Available from maxqda.com.

Whole Woman's Health v. Hellerstedt, 579 U.S. _ (2016).

Woodruff, K. \& Roberts, S. (2019). "My good friends on the other side of the aisle aren't bothered by those facts": U.S. State legislators' use of evidence in making policy on abortion. Contraception, 101(4): 249-255.

World Health Organization (2019). Preventing unsafe abortion. Retrieved from https://www.who.int/news-room/fact-sheets/detail/preventing-un safe-abortion

(C) Erica Barton, Subasri Narasimhan, and Dabney P. Evans. Originally published in jGPHA (http://www.gapha.org/igpha/) May 15, 2021. This is an open-access article distributed under the terms of the Creative Commons Attribution Non-Commercial No-Derivatives License (http://creativecommons.org/licenses/by/4.0/), which permits unrestricted use, distribution, and reproduction in any medium, provided the original work ("first published in the Journal of the Georgia Public Health Association...") is properly cited with original URL and bibliographic citation information. The complete bibliographic information, a link to the original publication on http://www.gapha.jgpha.org/, as well as this copyright and license information must be included. 